\title{
Obtenção de modelos ortodônticos
}

\author{
Fernando Habib*, Leonardo de Aquino Fleischmann**, Sabrina Kívia Correia Gama**,

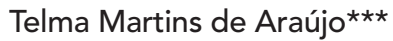

\begin{abstract}
Resumo
Introdução: os modelos de estudo são fundamentais no diagnóstico e planejamento do tratamento ortodôntico, uma vez que, através deles, pode-se visualizar os arcos dentários em três dimensões. Além de servirem de referência para avaliação da condução do tratamento nas mais diferentes fases, são considerados uma das formas de registro legal. Objetivo: este artigo apresenta uma técnica de recorte, acabamento e polimento de modelos ortodônticos.
\end{abstract}

Palavras-chave: Diagnóstico bucal. Ortodontia. Modelos dentários.

\section{INTRODUÇÃO}

Os modelos de gesso dos arcos dentários são considerados um elemento fundamental no diagnóstico em Ortodontia ${ }^{8}$ e uma das fontes de informação mais importantes, já que eles asseguram um registro permanente da má oclusão em três dimensões ${ }^{4,6}$. Com esses, pode-se melhor observar detalhes importantes, que muitas vezes são difíceis de serem visualizados na boca, analisar a simetria e forma dos arcos, inclinação, anatomia, tamanho e posição dos dentes, bem como permitem diferentes análises ortodônticas ${ }^{3}$. Além disso, constituem-se em valiosa forma de registro legal ${ }^{2}$, sendo de grande utilidade na comparação das diferentes fases do tratamento e transferência de pacientes entre profissionais ${ }^{11}$.

Quando confeccionados para fins ortodônticos, devem ser recortados de forma que suas bases fiquem simétricas. Existem dois motivos para isto: (1) se os modelos são recortados de modo que uma base simétrica seja obtida a partir da linha média do palato, é muito mais fácil analisar a forma do arco e detectar assimetrias intra-arcos; (2) modelos cuidadosamente recortados e polidos são mais aceitáveis para apresentação ao paciente e seus pais, causando uma reação psicológica favorável, o que poderá ser necessário durante consultas no decorrer do tratamento ortodôntico ${ }^{4,7}$.

Um modelo de estudo é constituído de duas partes: uma porção anatômica (unidades dentárias, vestíbulo bucal, freios e bridas) e uma porção artística, que é necessária para auxiliar no manuseio dos modelos, individualmente ou intercuspidados, e também proteger os dentes de fraturas $^{6}$, além de dar visualmente um aspecto equilibrado e agradável aos mesmos. A porção anatômica consiste em dois terços da distância da borda incisal à região mais profunda do vestíbulo. A parte artística compõe-se do terço restante, correspondendo à base.

* Professor Responsável pela Disciplina de Ortodontia da FOUFBA. Professor do Curso de Especialização de Ortodontia da FOUFBA.

** Alunos do Curso de Especialização em Ortodontia e Ortopedia Facial da FOUFBA.

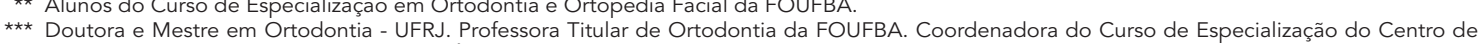
Ortodontia e Ortopedia Facial Prof. José Édimo Soares Martins - FOUFBA. Diretora do Board Brasileiro de Ortodontia e Ortopedia Facial. 
A obtenção de modelos ideais, a partir de moldagens bem executadas, é ponto fundamental para análise de um caso ${ }^{1}$. As moldagens devem se estender o máximo possível para o sulco vestibular, de maneira a permitir uma reprodução precisa de toda a anatomia do tecido mole ${ }^{5}$.

Os modelos deverão ser recortados na posição de máxima intercuspidação ${ }^{5}$. Porém, quando se tem uma grande diferença entre oclusão e relação cêntrica, deve-se obter um segundo par de modelos na posição de relação cêntrica. O preparo da porção anatômica deve limitar-se à remoção de bolhas positivas ou preenchimento de bolhas negativas ocorridas durante o processo de modelagem. Causar alterações na anatomia dentária é considerado falsificação de dados ${ }^{5}$. Segundo Strang ${ }^{10}$, os modelos artísticos preparados uniformemente, e equilibrados quanto às proporções das partes basal e anatômica, não apenas apresentam uma aparência agradável aos olhos como também refletem a qualidade e o zelo do ortodontista.

A forma mais adequada para obtenção de modelos ortodônticos é através do recorte de suas bases, obedecendo determinados critérios. A maneira que será descrita, nesta apresentação, é realizada em vários programas de pós-graduação no Brasil e no exterior, com apenas algumas variações, de acordo com cada escola. A proposta, então, é apresentar o modo de recorte realizado no Curso de

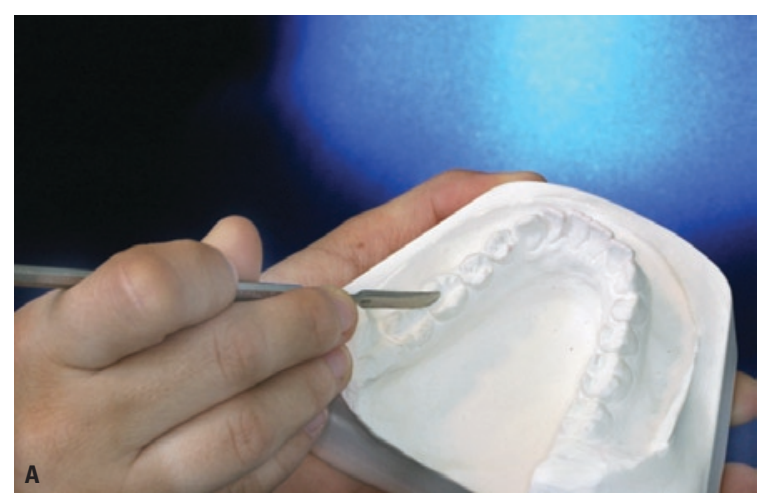

FIGURA 1 - Toalete dos modelos: A) nos dentes e B) nas bordas posteriores.
Especialização do Centro de Ortodontia e Ortopedia Facial Prof. José Édimo Soares Martins da Universidade Federal da Bahia.

\section{MATERIAL}

Para a realização deste procedimento, são necessários os seguintes materiais: estilete, faca para gesso, sonda exploradora $n^{\circ} 5$, espátula Lecron, lápis grafite, paralelômetro, recortador de gesso, guia angulada, placa de vidro, cera de articulação, esquadro, placa reticulada de Schmuth (simetroscópio), gesso pedra tipo II, conta-gotas, espátula de manipulação $n^{\circ} 24$, pedra de carborundum, lixas d'água $\left(n^{\circ} 400\right.$ e $\left.n^{\circ} 600\right)$, papel absorvente, solução de sabão, algodão e tecido de seda.

\section{MÉTODO}

Para obtenção de um par de modelos ortodônticos adequado, é importante obedecer de forma criteriosa os passos que serão descritos a seguir.

\section{Toalete}

Consiste na remoção de eventuais bolhas positivas que possam interferir no recorte ou intercuspidação dos dentes (Fig. 1A). Excesso de material que não corresponda à anatomia do vestíbulo ou área lingual também deve ser removido. Para tanto, recomendamos utilizar sonda exploradora $n^{\circ} 5$ $\left(\right.$ Duflex $^{\circledR}$ ) ou espátula Lecron $\left(\right.$ Duflex $\left.^{\circledR}\right)$. Deve-se, também, fazer a remoção das interferências nas

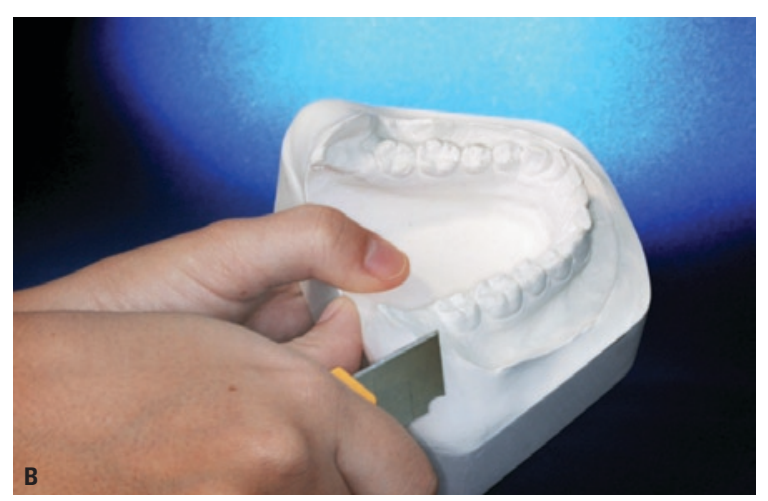


bordas posteriores, geradas devido ao excesso de gesso resultante do processo de modelagem, utilizando-se para isto um estilete $\left(\mathrm{CIS}^{\circledast}{ }^{\circledast}\right.$ ou faca para gesso $\left(\right.$ Jon $\left.^{\circledR}\right)$ (Fig. 1B).

\section{Hidratação das bases}

Deve ser realizada por cerca de 20 minutos, a fim de diminuir a resistência do gesso no momento do recorte (Fig. 2A). Atentar para que a área anatômica não sofra este processo. Tal precaução tem por objetivo evitar fraturas dos dentes, freios e bridas durante o recorte. Para tanto, colocar os modelos em recipiente com água até a metade das bases.

\section{Recortes}

\section{Base do modelo superior}

Obtém-se o registro do plano oclusal do modelo superior numa lâmina de cera amarela para
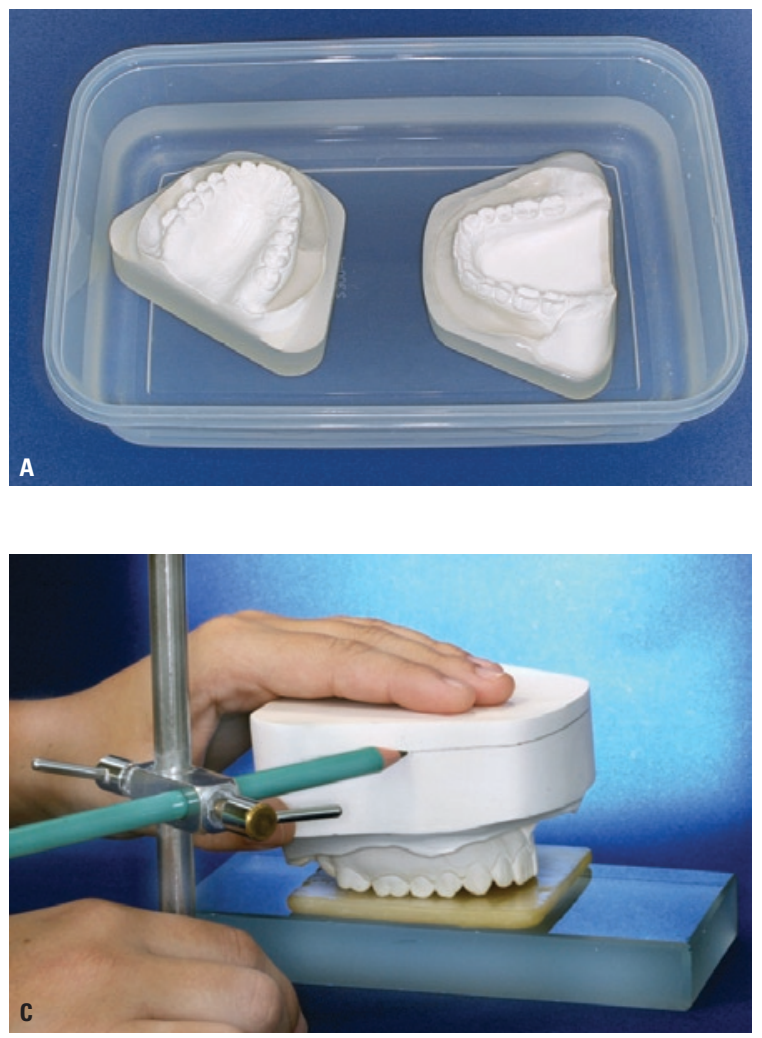

FIGURA 2 - A) Hidratação das bases dos modelos. B) Paralelômetro. C) Transferência do plano oclusal para a base do modelo superior. D) Recorte da base orientado pela marcação obtida.

articulação (Wilson ${ }^{\circledR}$ ) posicionada sobre uma placa de vidro, a qual deve estar assentada sobre uma bancada, de maneira que o maior número de dentes esteja em contato com a superfície da cera, reproduzindo o plano oclusal clínico do paciente (Fig. 2C). Utilizando paralelômetro (Hum$\left.\mathrm{pa}^{\circledR}\right)$ com um lápis acoplado, posicionado sobre a bancada (Fig. 2B), transferir o plano oclusal para a base do modelo (Fig. 2C), a fim de que a porção artística deste corresponda a $1 / 3$ da altura total final, restando então $2 / 3$ para a porção anatômica. Realizado este passo, procede-se ao recorte da base do modelo superior no recortador de gesso (Metal Vander ${ }^{\circledR}$ ) (Fig. 2D). Em seguida, colocar a superfície recortada sobre a bancada e observar a uniformidade e planificação da mesma, não devendo apresentar báscula. $\mathrm{O}$ recorte obtido deve estar paralelo ao plano oclusal.
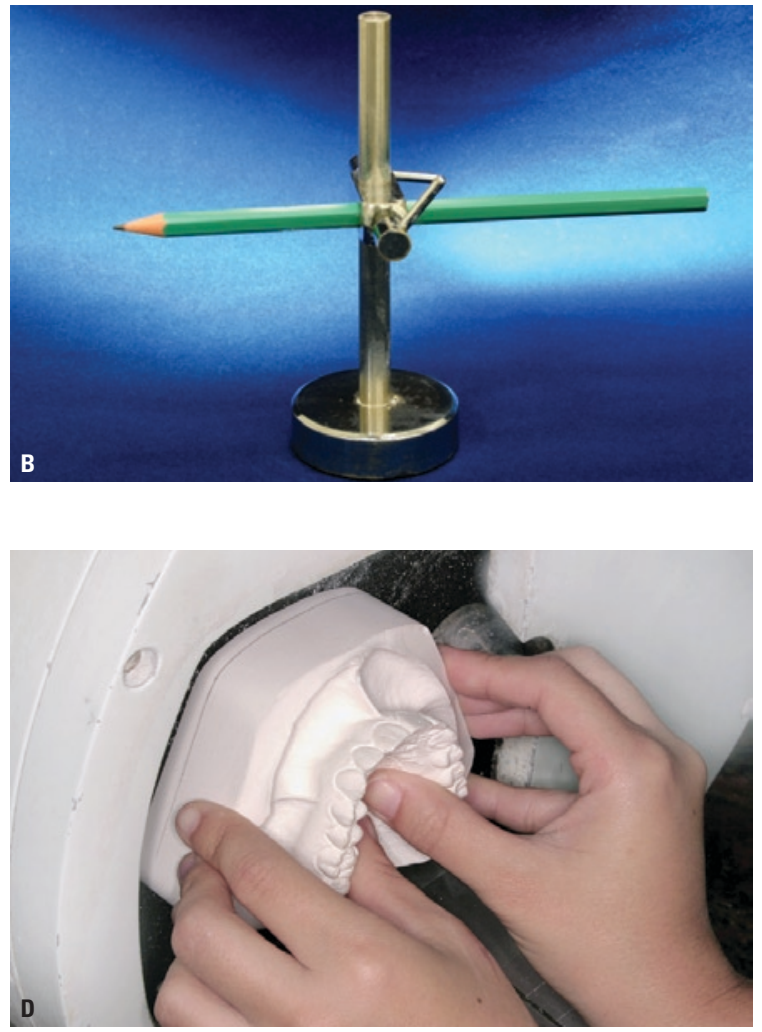


\section{Borda posterior do modelo superior}

Para isto, deverá ser feita a marcação de dois pontos centrais na rafe palatina mediana (Fig. 3A). Usualmente, em modelos com dentadura permanente, estes pontos são registrados na altura correspondente à mesial dos segundos pré-molares e dos primeiros molares. Posicionar a Placa de Schmuth (Tecnident $^{\circledR}$ ) (Fig. 3B) sobre a superfície oclusal do modelo superior, de forma que o centro desta coincida com os dois pontos previamente identificados sobre a rafe palatina mediana. Delimitar a borda posterior do modelo, através de uma linha realizada com lápis grafite, tendo cuidado especial para preservar os reparos anatômicos presentes na região - no caso, os últimos dentes e a tuberosidade (Fig. 3C). Quando do recorte desta área posterior, uma atenção especial deve ser dispensada às más oclusões severas de Classe II e III de Angle, que necessitarão de um maior espaço para articulação com o modelo antagonista, devido ao relacionamento ântero-posterior dos arcos dentários. O recorte da borda posterior do modelo superior deve ser realizado levando-o ao recortador, com sua base apoiada sobre a plataforma do mesmo (Fig. 3D). Procede-se ao recorte da região posterior até a linha previamente delimitada (Fig. 3E).

\section{Faces laterais do modelo superior}

Para realizar este passo, a guia angulada da máquina deverá estar em $65^{\circ}$ (Fig. 4 A,B). O recorte deve se estender até o início da porção anatômica, cuidando-se para deixar ambos os lados proporcionais (Fig. 4C). Porém, vale ressaltar que, em casos de assimetrias, isto nem sempre é possível.

\section{Região anterior do modelo superior}

Para tanto, a base posterior do mesmo deverá estar em contato com o cursor do recortador, ajustado em $30^{\circ}$ para o recorte de cada lado (Fig. 5A). Cada face da região anterior (direita e esquerda) deverá ter um comprimento de aproximadamente $3 \mathrm{~cm}$ e o vértice estar coincidente com a rafe palatina mediana (Fig. 5B).
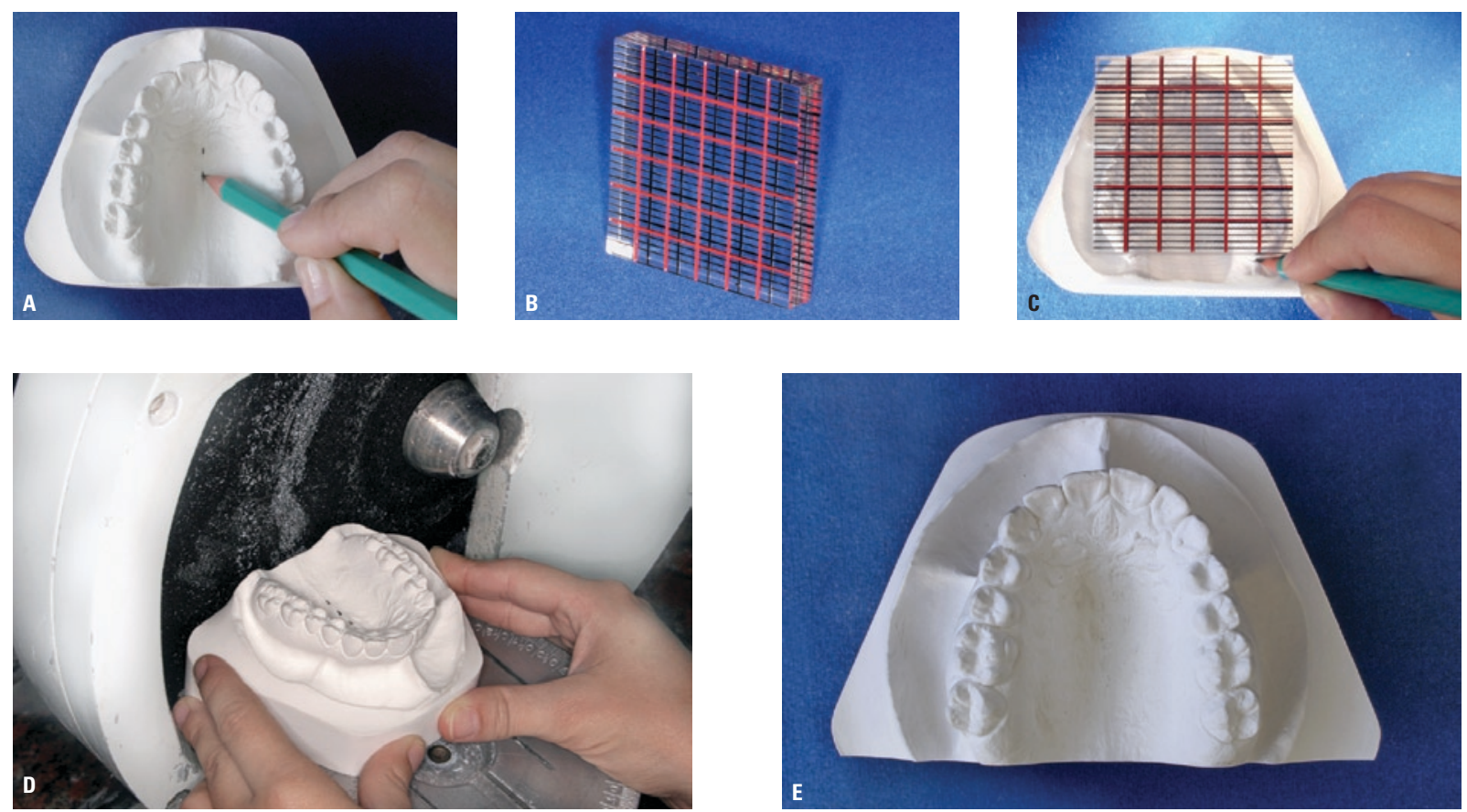

FIGURA 3 - A) Identificação de pontos na rafe palatina mediana. B) Placa reticulada de Schmuth. C) Delimitação da borda posterior do modelo superior. D) Recorte da borda posterior do modelo superior. E) Borda posterior do modelo superior recortada. 

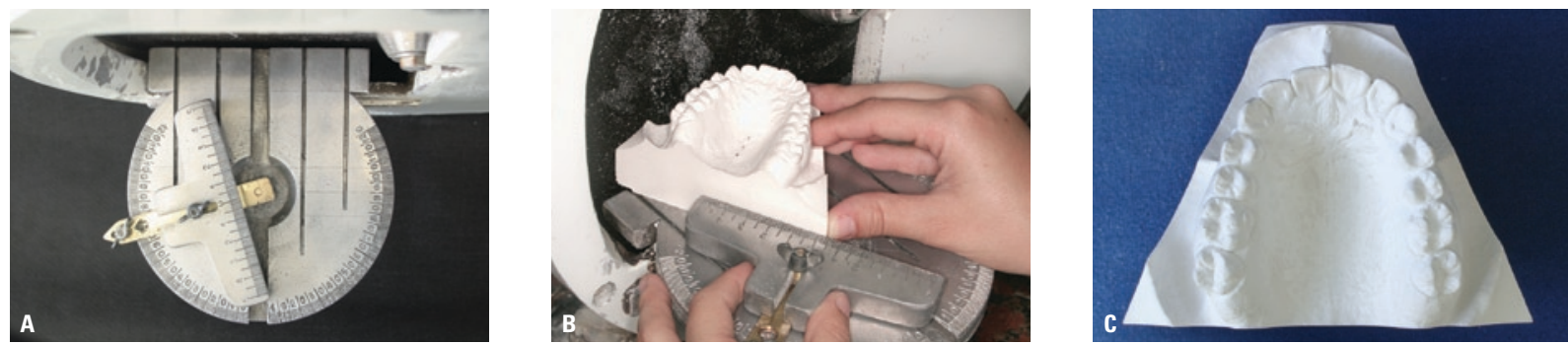

FIGURA 4 - A) Plataforma e guia angulada do recortador. B) Recorte lateral do modelo superior. C) Aspecto oclusal após o recortes laterais.
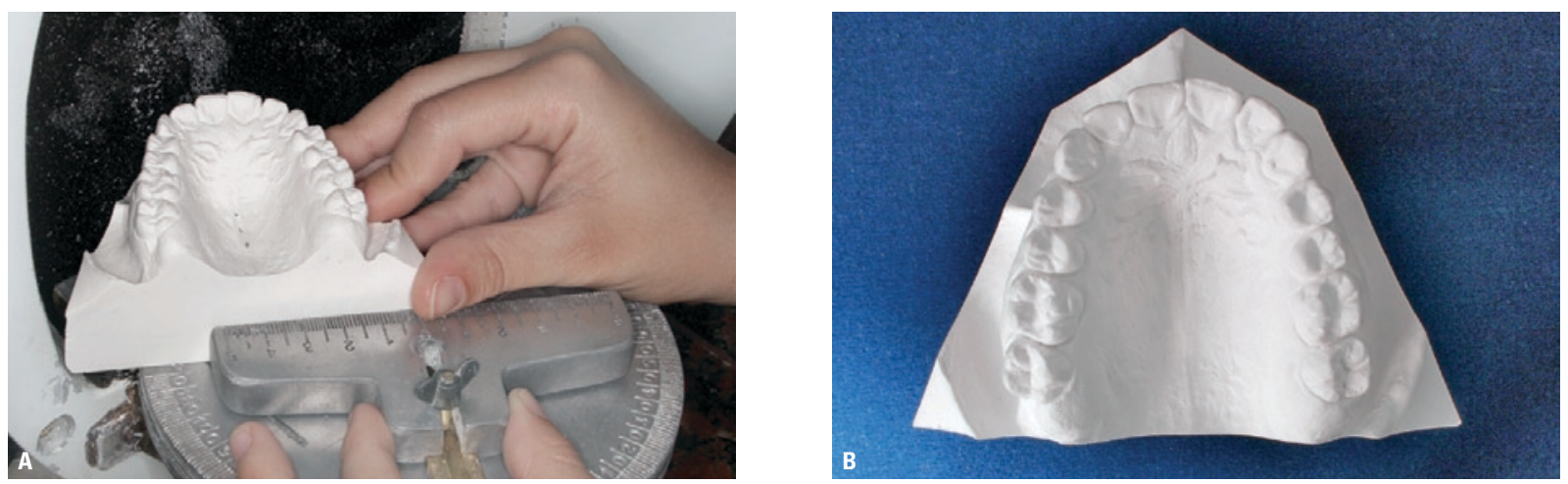

FIGURA 5 - A) Modelo posicionado para recorte da região anterior. B) Aspecto oclusal da região anterior após o recorte.
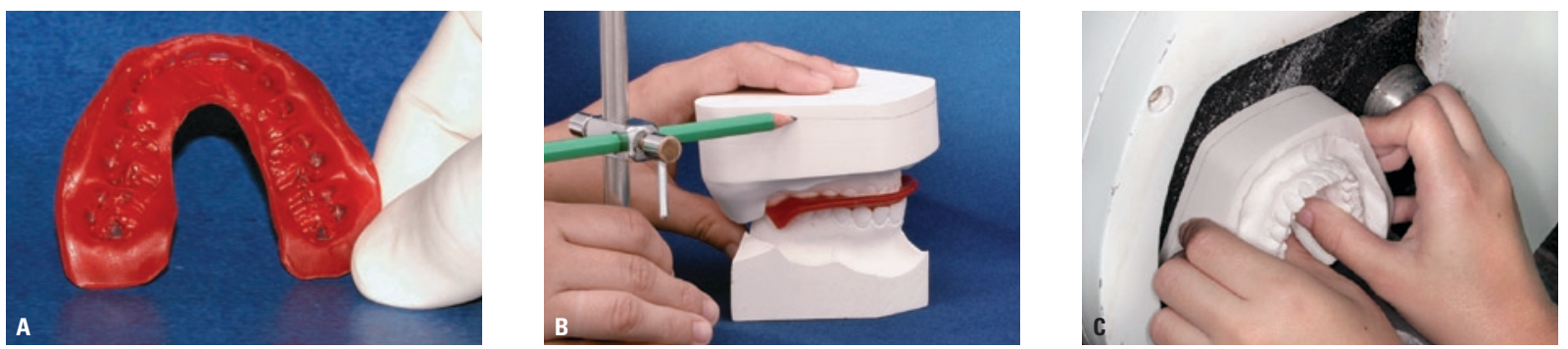

FIGURA 6 - A) Registro da oclusão do paciente. B) Transferência do plano oclusal superior para o modelo inferior. C) Recorte da base do modelo inferior.

\section{Base do modelo inferior}

Para isto, o plano oclusal do modelo superior deve ser transferido para a base do inferior. Esta transferência deve ser realizada estando os modelos ocluídos em relação cêntrica, com o registro da oclusão do paciente em cera rosa $n^{\circ} 7$ (Fig. 6A), obtido clinicamente, logo após o procedimento de moldagem. A base do modelo superior deverá estar voltada para baixo, apoiada sobre uma superfície plana. Transferir o plano oclusal para a base do modelo inferior, utilizando o paralelômetro (Fig. 6B). A altura total dos modelos articulados deve medir entre 7,5 e $8,5 \mathrm{~cm}$. A base do modelo inferior deve ser recortada até a linha previamente marcada, que representa o plano oclusal do paciente (Fig. 6C).

\section{Borda posterior do modelo inferior}

Os modelos devem estar articulados em oclu- 
são cêntrica com o registro de mordida do paciente (visando proteger a superfície oclusal dos dentes) e serem levados, assentados sobre a plataforma, com o modelo inferior para baixo, em direção ao disco de carborundum do recortador. O limite deste recorte é a área correspondente à borda posterior do modelo superior previamente recortado (Fig. 7A).

\section{Faces laterais do modelo inferior}

Neste momento, o cursor do recortador deverá estar em $60^{\circ}$, para cada lado, e o recorte ser estendido até o início da porção anatômica vestibular, conferindo simetria, sempre que possível (Fig. 7B, C).

\section{Faces póstero-laterais}

Para tanto, a linha média do modelo superior é transferida para a borda posterior, usando a placa de Schmuth e os dois pontos previamente marcados na rafe palatina (Fig. 8A). Com o auxílio de um esquadro, sobre a bancada, registra-se a extensão da linha média na região posterior do modelo superior (Fig. 8B). Após este procedimento, com
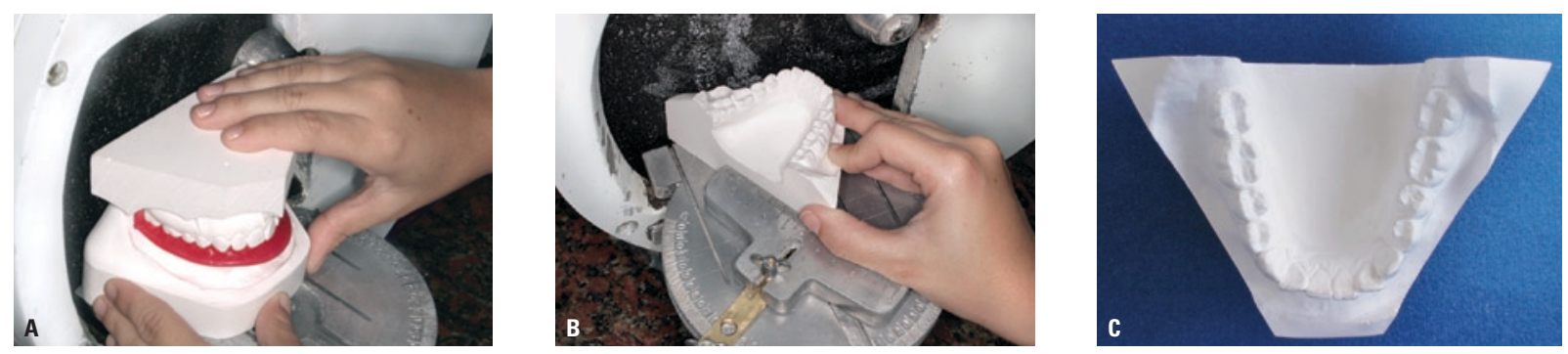

FIGURA 7 - A) Recorte da borda posterior do modelo inferior. B) Modelo posicionado para recorte da face lateral do modelo inferior. C) Aspecto oclusal após os recortes laterais.
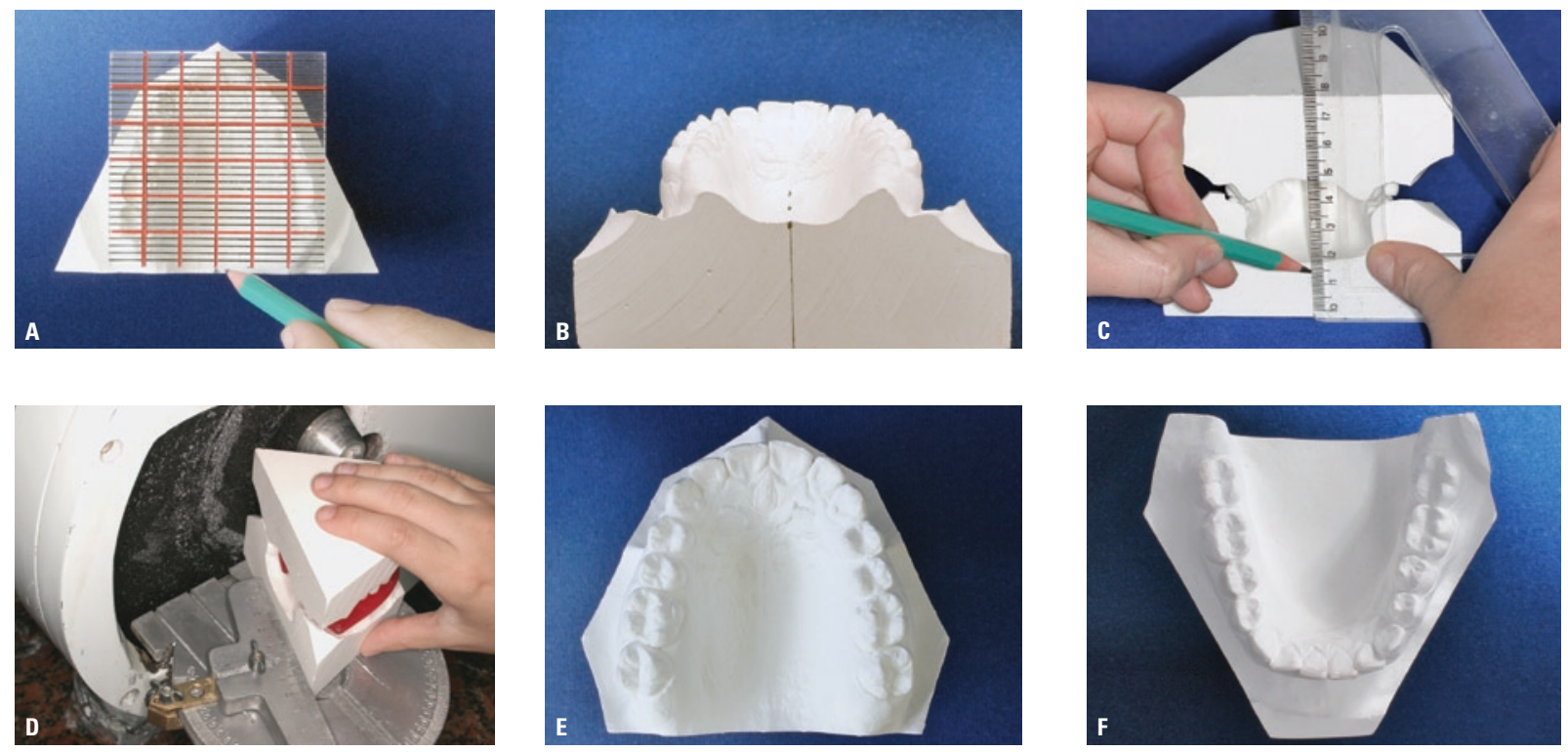

FIGURA 8 - A) Transferência da linha média para a borda posterior. B) Linha média transferida para a borda posterior do modelo superior. C) Transferência da linha média superior para o modelo inferior. D) Recorte das faces póstero-laterais com os modelos articulados. E) Aspecto oclusal do recorte póstero-lateral do modelo superior. F) Aspecto oclusal do recorte póstero-lateral do modelo inferior. 
os modelos articulados, transfere-se a extensão da linha média do modelo superior para a borda posterior do inferior (Fig. 8C). Esta referência é importante para obtenção de distâncias simétricas da linha média às áreas póstero-laterais. Os recortes das faces póstero-laterais são realizados com os modelos ocluídos e o cursor do recortador ajustado em $110^{\circ}$, para cada lado (Fig. 8D, E, F). Inicialmente, os modelos devem estar articulados com registro da oclusão em cera, pois, sem ele, há o risco de desgastar ou fraturar a superfície oclusal dos dentes. Posteriormente, se necessário, removese esse registro, a fim de realizar o ajuste final.

\section{Região anterior do modelo inferior}

Deve-se obter uma forma arredondada que vai do longo eixo do canino de um lado à mesma referência do canino oposto (Fig. 9B, C). Para transferir a posição do canino para a base do modelo, deve-se lançar mão de um esquadro posicionado numa superfície plana (Fig. 9A). Na presença de assimetria dos caninos, a linha média do modelo superior, que foi previamente transferida para a borda posterior do modelo inferior (Fig. 8C), deve ser estendida para a base do mesmo (Fig. 9D). Esta linha deverá ser prolongada até a região ântero-inferior (Fig. 9E) e servirá de referência para a obtenção de mais três linhas imaginárias, a saber: linha $\mathrm{X}$ - representa o prolongamento da linha vertical sobre o modelo inferior; linha Y perpendicular à linha $\mathrm{X}$, traçada sobre as bordas incisais das unidades situadas mais anteriormente, e linha $\mathrm{Z}$ - paralela à linha $\mathrm{Y}$, distando aproximadamente 6mm (Fig. 9F). Desta forma, a linha $\mathrm{Z}$ projetada sobre a base do modelo (lados direito e esquerdo) poderá representar um auxílio para determinação dos limites do recorte da região anterior nos casos de assimetrias dentárias.

\section{ACABAMENTO}

Após o recorte dos modelos, o próximo passo a ser realizado é o acabamento, que consiste na planificação da parte artística, calafetação, desidratação dos modelos e perolização.

Inicialmente, deve-se uniformizar as bordas entre a parte anatômica e artística na região pos-
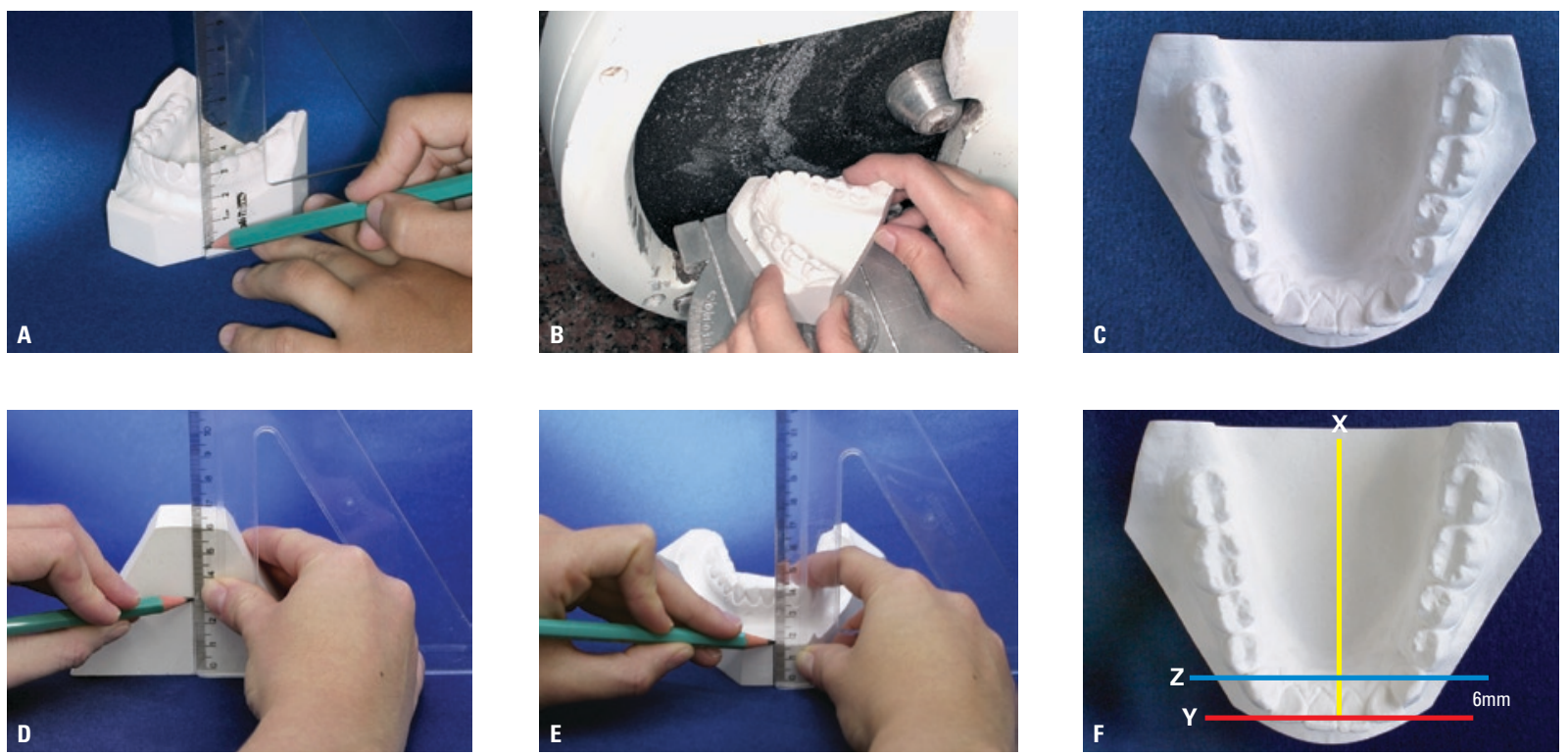

FIGURA 9 - A) Registro do longo eixo do canino. B) Recorte da região anterior do modelo inferior. C) Aspecto da região anterior do modelo inferior após o recorte. D, E, F) Delimitação das referências para o recorte ântero-inferior nos casos de assimetria dos caninos. 
terior dos modelos superior (tuberosidade) e inferior (trígono retromolar e região lingual). Cuidado especial deve ser tomado para não modificar a porção anatômica lingual do rebordo alveolar (Fig. $10 \mathrm{~A})$.

\section{Planificação da parte artística}

Utilizar lixa d'água n ${ }^{\circ} 400$ hidratada, estendida sob uma pedra de carborundun $\left(\right.$ Norton $^{\circledR}$ ), para aplainar as regiões da parte artística do modelo, tomando-se o cuidado de manter os ângulos do recorte "vivos". Ao realizar este procedimento, nas bordas posteriores e póstero-laterais, os modelos devem estar articulados com o auxílio do registro da oclusão do paciente em cera (Fig. 10B). Após o uso de lixa d'água $n^{\circ} 400$, utilizar a de $n^{\circ} 600$, seguindo as mesmas orientações.
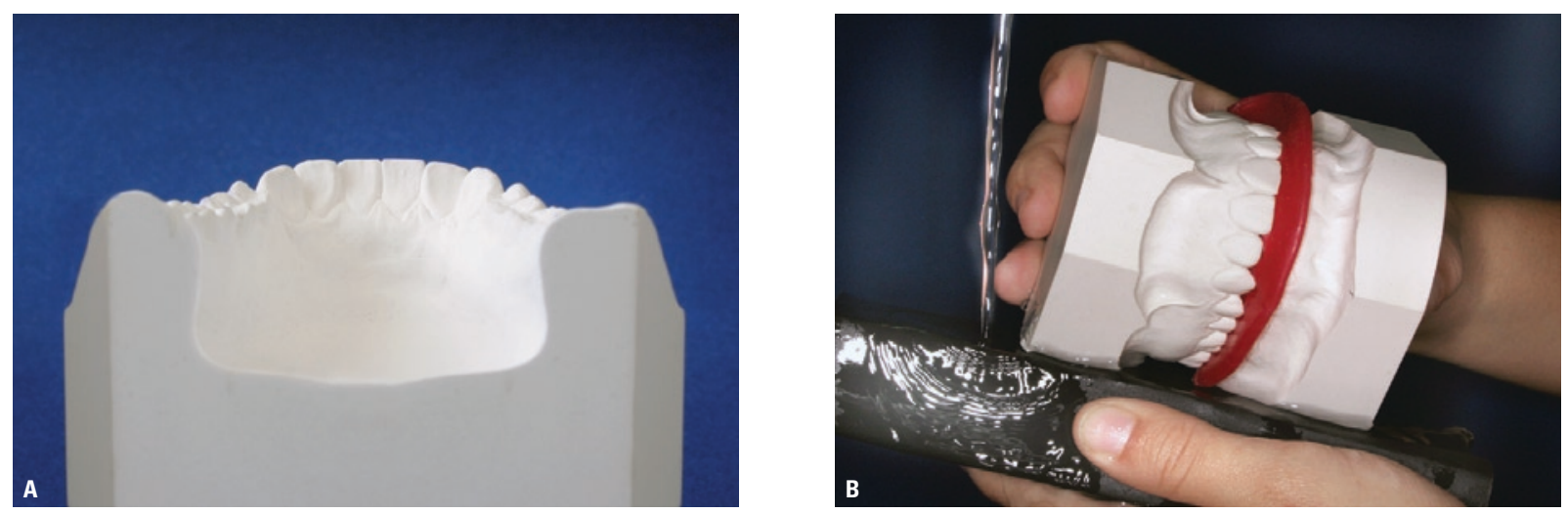

FIGURA 10 - A) Vista posterior do modelo inferior recortado. B) Utilização das lixas de acabamento.
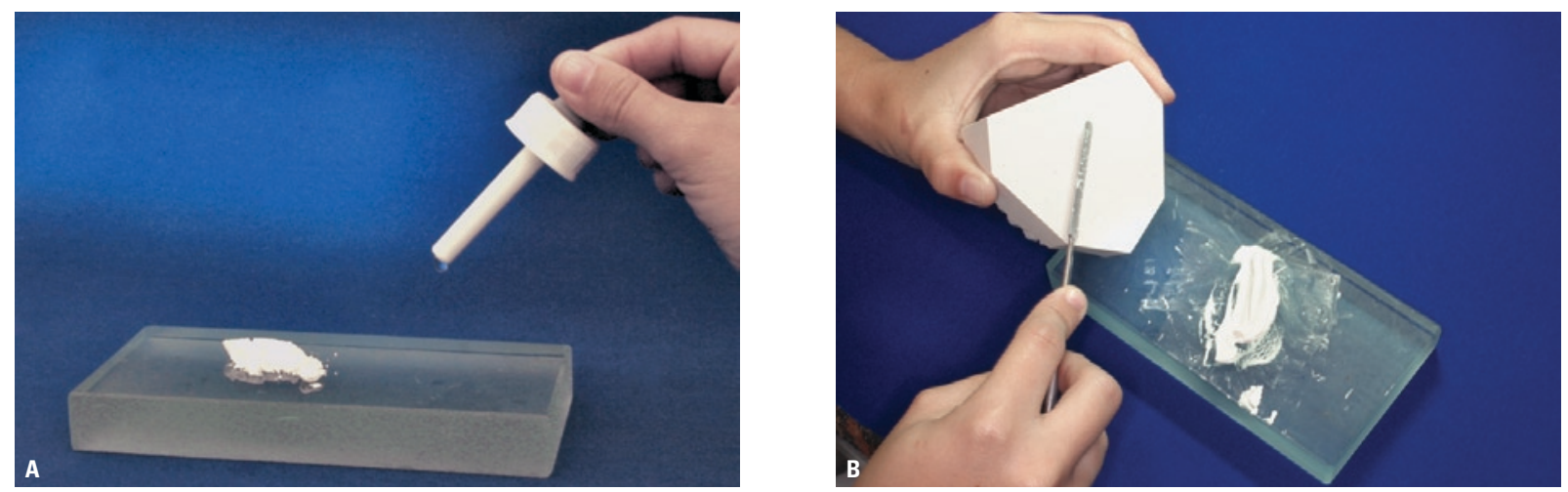

FIGURA 11 - A) Material para calafetação. B) Calafetação sendo executada com auxílio de espátula de manipulação nº 24. 


\section{Perolização}

O procedimento de perolização consiste em promover o acabamento final dos modelos, conferindo aos mesmos um aspecto estético mais agradável e uma maior resistência. Inicialmente devem ser mergulhados numa solução de sabão por 2 horas, com os dentes voltados para baixo (Fig. 12A), fazendo com que todas as superfícies dos modelos estejam imersas.

Essa solução pode ser adquirida no mercado ou preparada conforme a orientação a seguir: dissolver 250 gramas de sabão de coco em pó em 1 (um) litro de água quente sem ferver, para evitar a formação de espuma. Adicionar 20 gramas de ácido bórico, quando o sabão estiver totalmente dissolvido, e, por fim, deixar esfriar e coar em um pano branco limpo.

Em seguida, os modelos devem ser removidos e lavados em água corrente, sendo friccionados com algodão, porém, com o cuidado necessário para não alterar as estruturas anatômicas dentárias e do vestíbulo. Deixar secar por 24 horas em ambiente isento de poeira, com os dentes voltados para baixo, sobre papel absorvente. Após a completa desidratação, polir com tecido de seda (Fig. 12B).

Ao final destes passos, têm-se modelos bem recortados e polidos, com as unidades dentárias, o vestíbulo bucal, freios e bridas preservados (Fig. $13 \mathrm{~A}, \mathrm{~B}, \mathrm{C})$.

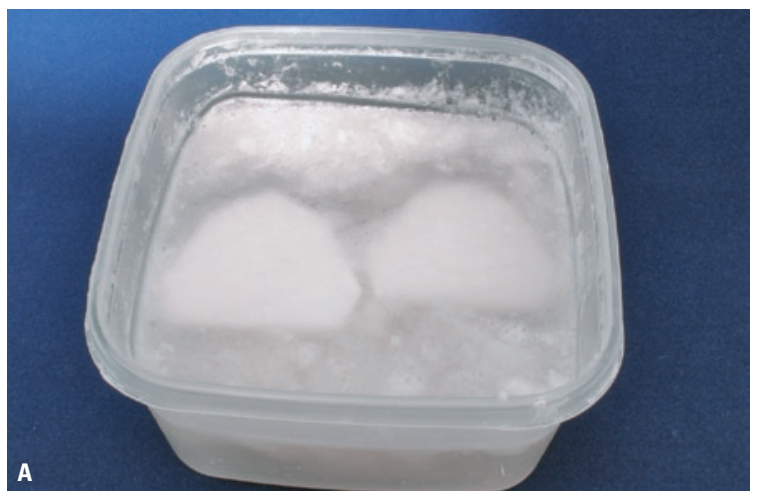

\section{IDENTIFICAÇÃO}

Os modelos devem ser identificados (Fig. 14), em sua base, a fim de proporcionar um arquivo organizado e prático para o ortodontista. Neles devem estar contidas informações importantes para facilitar o manejo do acervo, como:

- número do paciente, criado pelo ortodontista, de acordo com seu arquivo, acompanhado pelo ano em que o modelo foi obtido, ex.: 0307/05;

- nome do paciente;

- data da obtenção da moldagem;

- idade do paciente, composta pelo ano e mês;

- símbolo (círculo) identificando a fase do tratamento, considerando a orientação universal de cor: inicial - preto, reestudo - azul, final - vermelho, contenção - verde e pós-contenção - marrom ${ }^{9}$.

\section{CONSIDERAÇÕES FINAIS}

Os modelos de gesso representam uma visão tridimensional da má oclusão e permitem análise criteriosa dos arcos dentários superior e inferior, bem como da oclusão, nos aspectos vertical, transverso e ântero-posterior.

A análise de modelos é um passo fundamental no estudo ortodôntico, daí a importância de se obterem modelos corretamente recortados e polidos. Em modelos ideais, pode-se conseguir informações acerca do alinhamento dos dentes, forma dos arcos, assimetrias, anatomia da abóbada palatina, más posições individuais dos dentes,

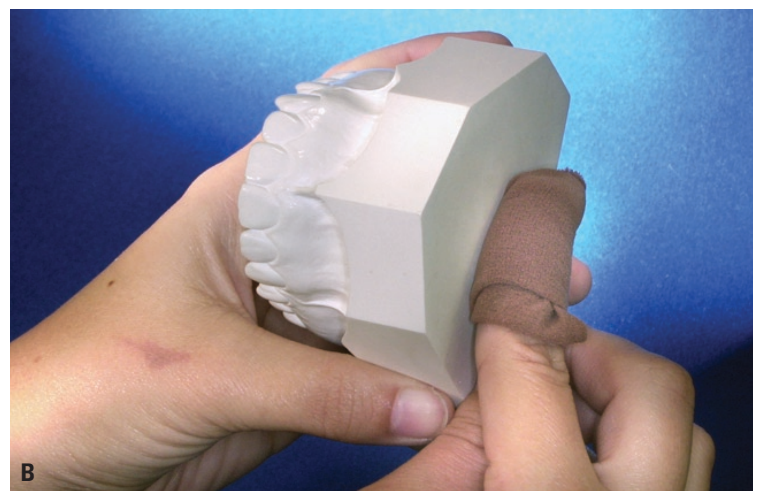

FIGURA 12 - A) Imersão dos modelos em solução de sabão. B) Polimento com tecido de seda. 

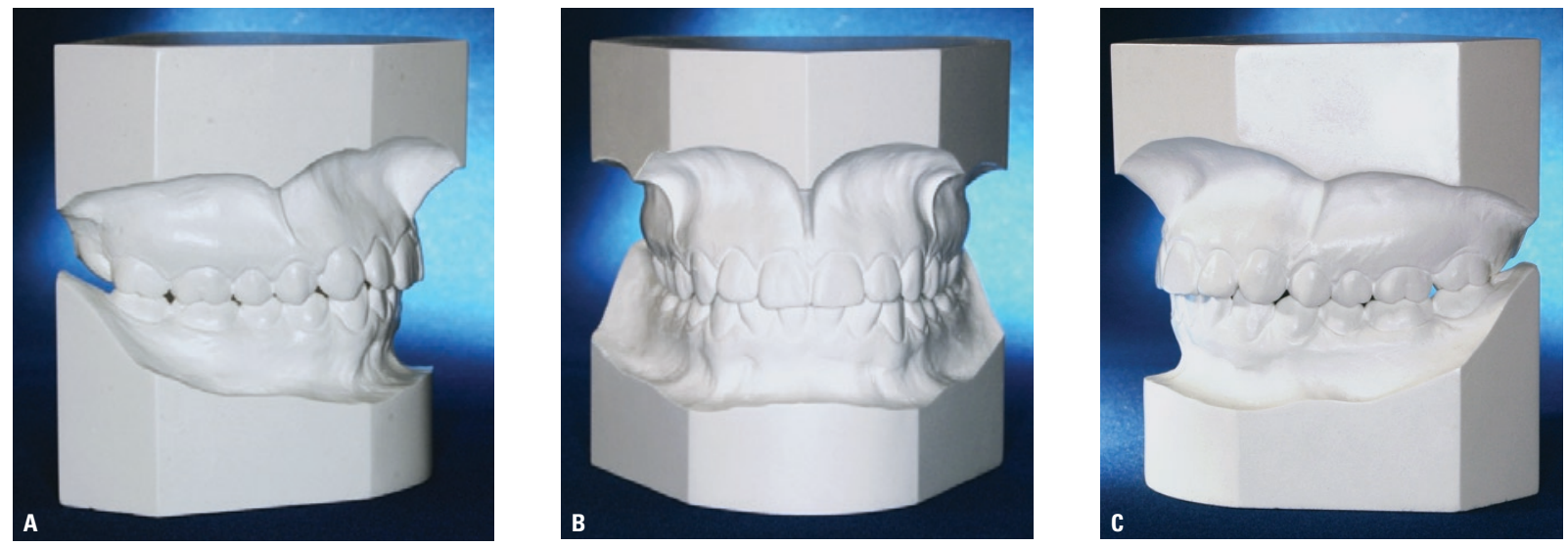

FIGURA 13 - Modelos recortados e polidos: A) vista lateral direita, B) vista frontal e C) vista lateral esquerda.

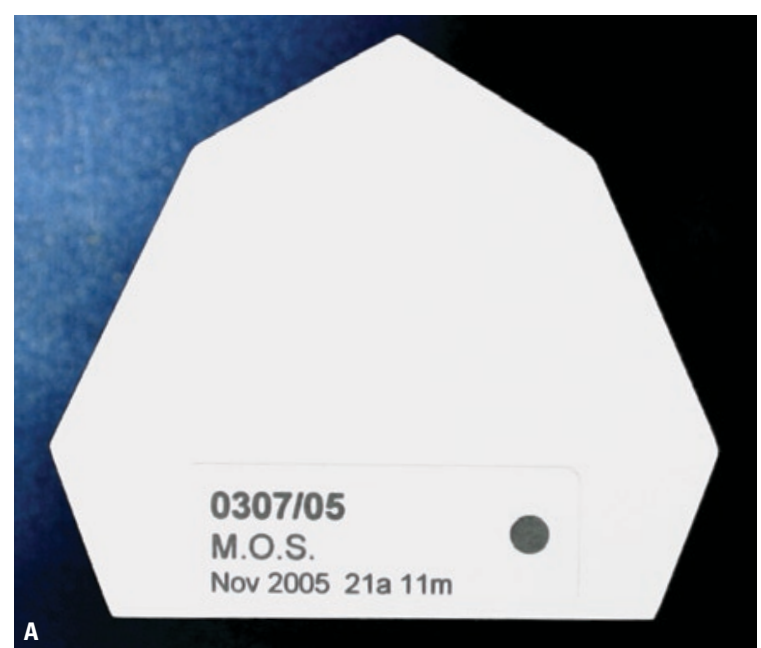

FIGURA 14 - Identificação dos modelos: A) superior e B) inferior.

relacionamento ântero-posterior e transverso dos arcos dentários e níveis de sobremordida e sobressaliência.

São, portanto, um instrumento indispensável no diagnóstico, planejamento, acompanhamento e avaliação do tratamento ortodôntico, além de serem um registro legal.

Porém, para que esta avaliação seja confiável, os modelos devem apresentar fidelidade da

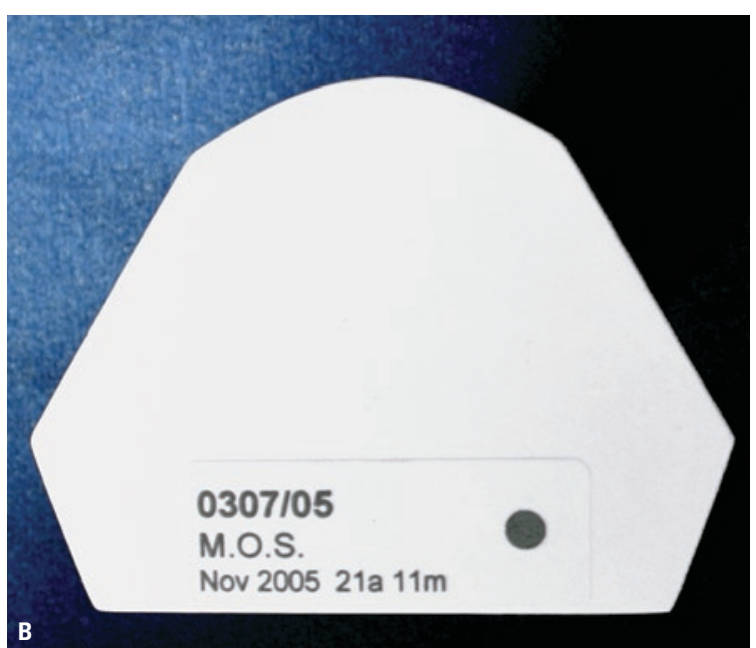

porção anatômica - unidades dentárias, vestíbulo bucal, freios e bridas - e estar corretamente recortados, com suas bases paralelas ao plano oclusal do arco superior e perpendicular à rafe palatina mediana. Vale ressaltar que, nos casos de assimetrias esqueléticas e dentárias severas, nem sempre é possível obter a proporcionalidade ideal, devendo prevalecer, nestas ocasiões, o bom senso do profissional. 


\section{AGRADECIMENTO}

Os autores agradecem à Semp Toshiba pela valiosa contribuição que tem emprestado ao Centro de Ortodontia e Ortopedia Facial Prof. José Édi- mo Soares Martins, da Faculdade de Odontologia da Universidade Federal da Bahia.

Enviado em: outubro de 2006 Revisado e aceito: dezembro de 2006

\title{
Trimming of orthodontic models
}

\author{
Abstract \\ Introduction: Plaster cast models are fundamentals in the diagnosis and treatment planning in Orthodontics. \\ The dental arches can be viewed in three dimensions and the models used as legal documentation for the ortho- \\ dontist. Aim: Therefore, the object of this paper is to describe the technic of trimming and finishing the models.
}

Key words: Oral diagnosis. Orthodontics. Dental models.

\section{REFERÊNCIAS}

1. ARAÚJO, M. G. M. Ortodontia para clínicos: programa préortodôntico. São Paulo: Ed. Santos, 1999.

2. AYOUB, A. F. et al. A three-dimensional imaging system for archiving dental study casts: a preliminary report. Int. J. Adult Orthodon. Orthognath Surg., Chicago, v. 12, no. 1, p. 79-84, 1997.

3. FERREIRA, F. V. Ortodontia: diagnóstico e planejamento clínico. São Paulo: Artes Médicas, 2002

4. GRABER, T. M.; VANARSDALL, R. L.; VIG, K. W. L. Orthodontics: current principles and techniques. Missouri: Elsevier Mosby, 2005

5. MANUAL do Candidato ao Board Brasileiro de Ortodontia [online] 2005. Disponível em: <http://www.bbo.org.br>. Acesso em: 12 jun. 2005.
6. MOYERS, R. E. Ortodontia. Rio de Janeiro: Guanabara Koogan, 1991.

7. PROFFIT, W. R. Ortodontia contemporânea. Rio de Janeiro: Guanabara Koogan, 2002.

8. RONCHIN, M. et al. Documentation file of orthodontic clinical records: plaster study models. Mondo Ortod., Milano, v. 14, no. 4, p. 443-457, 1989.

9. STEINER, C. C. Cephalometrics as a clinical tool. In: KRAUS, B. S.; RIEDEL, R. A. (Org.). Vistas in Orthodontics. Philadelphia: Lea \& Febiger, 1962. p. 131-162.

10. STRANG, R. H. W. A textbook of Orthodontics. Philadelphia, J. B. Lippincott, 1958.

11. TWEED, C. H. Clinical Orthodontics. St. Louis: C. V. Mosby, 1966.

\author{
Endereço de correspondência \\ Fernando Habib \\ Av. Araújo Pinho, 62, $7^{\circ}$ andar, Canela \\ CEP: 40.110-150 - Salvador / BA \\ E-mail: fhabib@terra.com.br
}

